states that in a factory where chlorine, sulphur dioxide, hydrofluoric acid, and combinations of phosgene with phosphorus oxychloride and phosphorus trichloride were manufactured "enough [hydrofluoric acid vapour] escaped into the atmosphere so that men with glasses could not work in the rooms, and the window panes were etched to the extent that the wind blew them out of their frames. The films of these men, employed at such work for four to ten or more years, showed no trace of reaction attributable to gas, and the incidence of tuberculosis was no greater than in persons employed in other parts of this large plant. Repeated examinations failed to demonstrate evidence of reactivation of several cases of latent apical disease that occurred in the group." He concluded that there was no evidence that any of the more common industrial fumes or gases alter susceptibility to tuberculosis.

REFERENCE
${ }^{2}$ Occupational Medicine and Industrial Hygiene, p. 403. St. Louis :

\section{Physiological Clocks}

Q. -What part of the central nervous system is concerned in estimating the passage of time? Normal man is capable of estimating the passage of, say, half an hour with remarkable accuracy, provided that he maintains his concentration. Apart from the disturbances of consciousness (coma, stupor, mescaline intoxication, etc.), are there any known organic neurological disorders in which appreciation of time becomes so distorted that a second passing seems like a millennium?

A.- Nothing is known of any localized centre in the brain acting as a timekeeper. There is no particular reason why the brain as a whole, or many parts in semi-independence, should not act in this way, if their function tended to vary with time. Apart from sensory appreciation of changes in the external world, the body is provided with a number of possible clocks-for instance, the filling of the bladder or colon, the exhaustion of glycogen stores in the liver, etc. Subjective appreciation of the passage of time is, as is well known, strongly influenced by emotional attitudes. Did not Shakespeare comment on this point? "Who doth he gallop withal ? With a thief to the gallows." (As You Like It : Act III, Sc. 2.) Appreciation of the passage of time is grossly altered in most disturbances of consciousness, deliria, etc. It is also very dependent on the formation of recent memories, and is therefore affected in Korsakoff's psychosis and similar states. A Korsakoff patient, after an hour's intensive investigation in an interview, may think he has been with the doctor for only a few minutes. There is a condition in which the passage of a second may seem a millennium-mescaline intoxication-but the mechanism is unknown.

\section{Psoralens and Vitiligo}

Q.-What are psoralens, and what is their place in the treatment of vitiligo?

A.- Reports, particularly in Egyptian and American literature, indicate that certain extracts of the fruit of the plant Ammi majus, which grows in Egypt, are effective in the treatment of vitiligo. Attempts are being made to synthesize these substances-ammoidin, ammidin, and majudin. They may be applied to the depigmented areas or may be taken internally, and subsequent exposure to ultra-violet light produces redness and blistering which is followed in a large proportion of cases by normal pigmentation of the affected areas.

\section{Pains in the Feet in Addison's Disease}

Q.-Are severe constant pains in the feet ever a feature in mild Addison's disease? If so, what are their cause and treatment?

A.- It cannot be said that severe constant pains in the feet are ever a feature of mild Addison's disease. Muscular cramps, usually in the calves, occur as a result of loss of sodium chloride and clear up with treatment with deoxycortone acetate and salt. It is possible that pains in the feet may similarly arise, although it is unlikely in mild Addison's disease. Another suggestion is that the pains in question may be due to flat feet, produced by the muscular weakness which is a characteristic feature of Addison's disease.

\section{Sleep-walking and Epilepsy}

Q.-Is there any relationship between sleep-walking and the later development of epilepsy? What treatment is advised for sleep-walking of very recent origin in a boy of 6 ?

A.- It is obviously possible that in an individual case sleep-walking might occur as a post-epileptic automatism after a nocturnal fit. Such an occurrence would be most unusual, and it must be remembered that sleep-walking is very common. So far as is known, there is no general relationship between sleep-walking and epilepsy.

Often the best treatment of sleep-walking is no treatment at all. This is so when it occurs only on isolated occasions in an otherwise well-adjusted child. The doctor's job is then to reassure the over-anxious parents. He can tell them that about $50 \%$ of children walk in their sleep once or twice in their lives, that it is in fact normal, and very rarely indeed likely to involve a risk. If reasonable safeguards are taken against such dangers as falling downstairs, there need be no concern. If sleep-walking is frequent and persistent, rather more notice should be taken. It may then be but one sign of a more general nervousness-caused by an element of emotional discord in the home, for instancewhich will need investigation and treatment. The symptom itself often responds to hypnosis and post-hypnotic suggestion.

\section{NOTES AND COMMENTS}

Heavily Furred Tongue.-Dr. A. Lowndes YATES (Canford Cliffs) writes: The clinical picture described in this question ("Any Questions?" May 9, p. 1061) would apparently correspond to that found in invasion of the epithelium of the tongue with the penetrating form of monilia and/or with the fungus torula, since both not infrequently exist together. The forms of monilia and torula which are present in normal healthy mouths produce no symptoms, but in the penetrating forms the spores invade first the superficial and later the deeper layers of epithelium, and in the latter case cause ulceration. Such an invasion of the epithelium by the spores is often accompanied by the symptoms of oesophagitis, with which certain of the symptoms mentioned in the clinical history of the case would correspond A smear taken from the tongue and stained would, if the diagnosis of monilial or torulal infiltration is correct, show some of the cells derived from deeper layers of epithelium which have been invaded by the spores. If this provisional diagnosis is confirmed by microscopical examination of a smear, the most satisfactory though messy treatment is by means of application of coloured dyes to the surface of the tongue, while about three grains of sulphathiazole applied as powder to the contact surface of the dentures may hasten the disappearance of the symptoms, which, however, do not yield with great rapidity to any form of treatment with the exception of radiation, which latter is apt to be followed by distressing dryness of the mouth which lasts for weeks or months.

Correction.--In our leading article "Homage to Lind" (June 6 , p. 1265) we should have added that the Royal Navy was also represented by Surgeon Vice-Admiral Sir Alexander InglebyMackenzie, medical director-general, who took the chair at the afternoon session on May 22 and read an address on Lind.

All communications with regard to editorial business should be addressed to THE EDITOR, British Medical Journal, B.M.A. House. Tavistock TELEGAMS: Aitiology, Westcent, London. ORIGINAL ARTICLES AND LETTERS forwarded for publication are understiod to be offered to the British Medical Journal alone unless the contrary be stated.

Authors desiring REPRINTS should communicate with the Publishin Manager, B.M.A. House, Tavistock Square, W. ..1. on receipt of proofs. Authors overseas should indicate on MSS. if reprints are required, as proofs are not sent abroad.

ADVERTISEMENTS should be addressed to the Advertisement Manager. B.M.A. House. Tavistock Square, London, W.C.1 (hours 's a.m. to 5 p.m.). TELEPHONE: EUSTON 4499. TELEGRAMS: Britmedads

MEMBERS' SUBSCRIPTIONS should be sent to the SECRETARY of the Association. TELEPHONE: EUSTON 4499. TELEgRAMS: Medisecra, Westcent, London.

B.M.A. ScotTish OFFICE: 7, Drumsheugh Gardens, Edinburgh 